\title{
Multiple Choice English Grammar Test Items That Aid English Grammar Learning for Students of English as a Foreign Language
}

\author{
D. Wagiman Adisutrisno \\ English Department, Faculty of Teacher Training and Education, \\ Widya Mandala Catholic University, \\ Dinoyo 42-44, Surabaya, East Java, Indonesia
}

\begin{abstract}
In the teaching of English as a foreign language in Indonesia, the teaching and testing of English grammar are indispensable. To test English grammar mastery, the multiple choice test must be used due to its merit of guaranteeing the fulfillment of the content validity of achievement tests. Unfortunately, the construction of many multiple choice test items has not been based on a very important consideration to aid learning processes. This paper discusses the need to use multiple choice test in English grammar achievement testing, two cognitive learning theories that underlie the importance of constructing multiple choice items that aid learning processes, and examples of faulty multiple choice test items and their revisions.
\end{abstract}

Key words: focus on form instruction, content validity, long term memory, non-occurrent forms

James Dean Brown (1996, p. 56) in his book Testing in Language Programs constructed the following English grammar test item as a model for English teachers to follow:

The boy stepped on a piece of ice and .............. flat on his face
a. fell
b. fall
c. felled
d. falled

The intended key is, of course, option $a$. fell. The content of the problem is the English simple past tense. Option $b$. fall, is not a content of tense, but concord between the subject and the predicator. This option causes the test item to contain a mixed content: a problem of tense and a 
problem of concord. In solving the problem, test takers or testees have to process two things: thinking about tenses and concord. Option $c$. felled, is a correct past tense form but the meaning is not "fall down" but "cut down" such as felling trees. This option causes testees to think about word meaning, a problem of semantics. Option $d$. falled, is a non occurrent form in English, that is, a form that does not exist in the English language. As in real life situations people do not use language forms that do not exist, this option may be interpreted as a correct form in English by uninformed testees. Hence, option $d$ misleads students' learning processes of English tense.

The following test item was constructed by an English teacher of a TV program in Indonesia:

The party (a. end b. ends c. ended) at 11 o'clock last night.

It is a good idea that this test item does not necessitate four options, as the desire to always have four options for all grammar test items may end up with undesirable faulty options. The correct option of this test item is $c$ : ended, the past tense form option $b$ : ends, is desirable because it is also a tense form. But option $a$ : end, is not a tense problem but a subjectpredicator concord problem. This option is, therefore, undesirable as it does not facilitate the students in their learning of English tenses.

The item below was constructed by an English language teacher in Indonesia:

What you ......... just now was quite difficult to understand
a. explain
b. explaining
c. explained
d. explains

This item poses a tense problem and the key is $c$ : explained. Option $a$ : explain, is desirable as it also pertains to tense. Option b: explaining, is not desirable because 'explaining' is not a correct, finite form of the predicator of the subject 'you'. Option d: explains is not desirable either since it poses a problem of subject-predicator concord, not a tense problem. This item has a mixed content.

This item was constructed by an English student teacher in Surabaya, Indonesia:

Miss Nanik and Miss Sandra works at school.

They teach Math. They are .................
a. teacher
c. teachers
b. teachers
d. teaches 
The predicator 'works' indicates that this English student teacher still has a language problem. This item poses a problem of plural noun. The key is option c: teachers. Option $a$ : teacher, is desirable since plural nouns are usually contrasted with singular nouns. Option $b$ : teachers is not desirable because it is a non-occurrent form. Option $d$ : teaches is not desirable either since it is a verb not a noun; besides, it poses a problem of subject-predicator concord.

My observation is that so far the English grammar test items which are constructed by language testing experts whose native language is English as well as English teachers in Indonesia have always contained approximately the same flaws as those described above. Such grammar test items have certainly not been constructed on the basis of the following very important principle: to aid, help, or facilitate students' learning processes of English grammar. This paper is written and disseminated to English teachers at all levels in Indonesia and possibly other countries in the world to add one more piece of information about constructing test items that help the learning processes of English grammar to arrive at accurate English grammar mastery. It will include the need for teaching English grammar and vocabulary, two very influential cognitive learning theories: the human information processing theory and Noam Chomsky's hypothesis-making theory, the merits of multiple-choice type test items, principles of constructing multiple-choice type test items, examples and discussion of faulty multiple-choice type English grammar test items.

\section{THE NEED FOR TEACHING ENGLISH GRAMMAR AND VOCABULARY}

For the last two decades or so, the structural approach to foreign language teaching has partly been replaced by the communicative approach. While the former is a foreign language teaching approach that focuses on the mastery of the grammatical rules and vocabulary of the foreign language in order to be able to write correct sentences, paragraphs, and compositions in the foreign language and understand reading texts in the foreign language, preferably literary works, the latter is an approach to foreign language teaching that focuses on expression of meaning, that is, the ability to comprehend the meaning of written and spoken discourse and the ability to produce meaning or ideas in written and spoken discourse. While the former lauds and aims at accurate knowledge of foreign 
language grammar and vocabulary, the latter emphasizes expression of meaning or ideas without requiring perfect knowledge of grammar and vocabulary. Even when knowledge of foreign language grammar and vocabulary is insufficient to express meaning or ideas, the use of the native language to express meaning is tolerated.

Both approaches have a weakness. With reference to the structural approach, accurate knowledge of foreign language grammar and vocabulary may not automatically result in good language performance that includes listening, speaking, reading, and writing. Intensive exercises in listening, speaking, reading, and writing in the foreign language are of paramount importance in order to be proficient in the foreign language. As for the communicative approach, an emphasis on language performance that includes listening, speaking, reading and writing results in students' inaccurate knowledge of foreign language grammar and vocabulary. Indeed, this lack of accurate knowledge of foreign language grammar and vocabulary has lately been detected and foreign language teaching experts have suggested to incorporate language forms, namely: words, phrases, clauses, sentence, and paragraphs including the various kinds of grammatical rules for the combination of words into larger units. Focus on form instruction has lately been clamored. Hinkel (2006) states that "research findings demonstrate that, without explicit and form-focused instruction, extensive exposure to meaning-based input does not lead to the development of syntactic and lexical accuracy in an L2" (p. 111). The same concern is expressed by Doughty and Williams (2004) in their book Focus on Form in Classroom Second Language Acquisition. The teaching of foreign language grammar and vocabulary is certainly indispensable. As a part of the teaching and learning program, the testing of foreign language grammar and vocabulary is absolutely essential.

\section{TWO INFLUENTIAL COGNITIVE LEARNING THEORIES: THE HUMAN INFORMATION PROCESSING THEORY AND NOAM CHOMSKY'S HYPOTHESIS- MAKING THEORY}

\section{The Human Information Processing Theory}

One of the cognitive learning theories that describes the psychological processes in problem solving is the human information processing theory. The following is the diagram of the human information processing theory: 


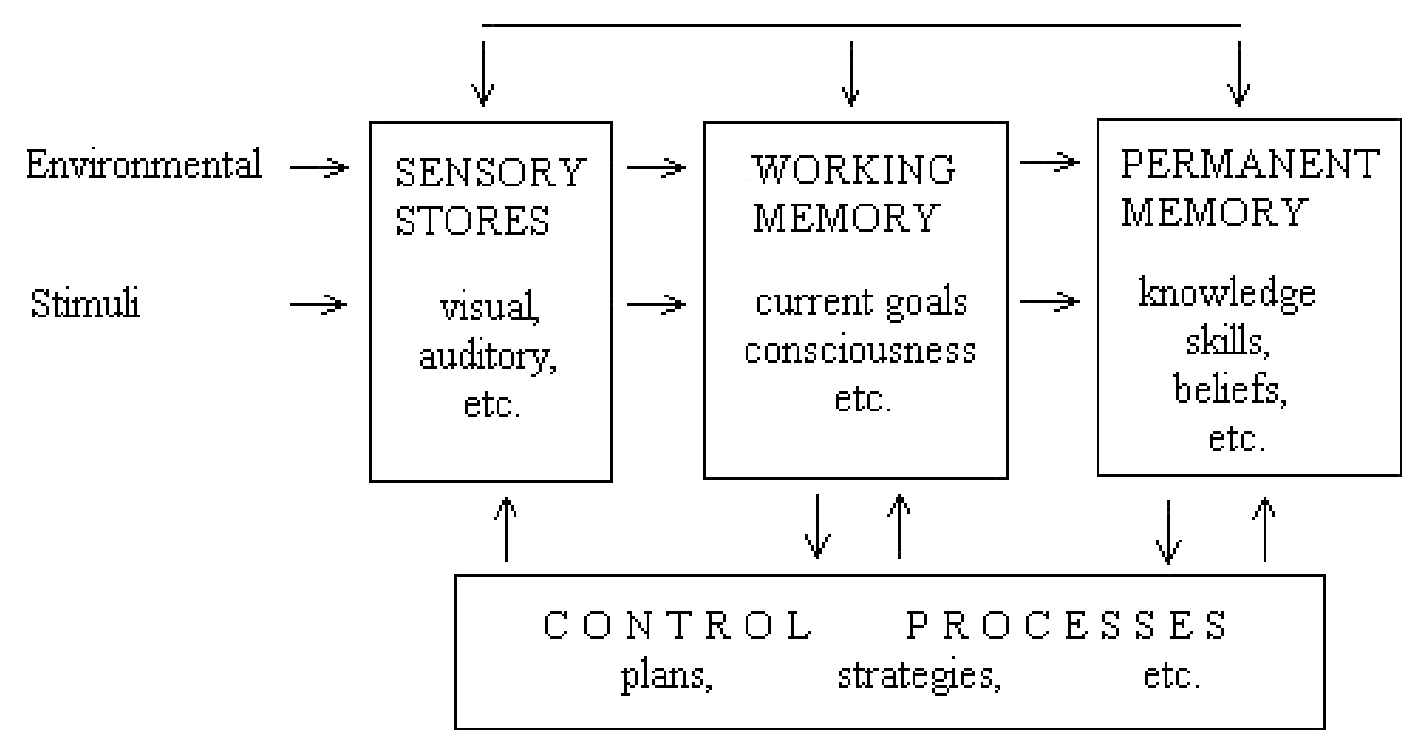

(Carroll, 1986, p. 46)

The first component of the human brain consists of sensory stores. Human sensory stores take in environmental stimuli by means of eyes, ears, and other channels. Visual stores, auditory stores, and other kinds of stores represent information in a literal and unanalyzed form. The sensory stores preserve the information long enough for initial processing to take place. Information processing begins by retrieving information or knowledge from permanent memory or long-term memory. People interpret a stimulus and recognize a pattern, a shape, a configuration, colors, melodies, tastes, and smells as familiar when they retrieve information from permanent memory that matches the new information. When the stimulus has been correctly interpreted and identified, it is, then, sent to the working memory for further processing.

The second component of the human brain is the working memory. Working memory also known as short-term memory or short-term buffer, holds information that is currently occupying our attention. The contents of working memory are in an active state and are nearly synonymous with immediate consciousness and awareness. Human mental acts are in fact complex series of decisions and it is necessary to have a temporary holding place for intermediate decisions. Since these acts can be completed quickly, the contents of the working memory are constantly changing.

Human short-term memory has limited capacity in holding information. It can hold approximately five to nine items of information per second. When it holds too many items of information, the short-term 
memory will be overloaded and further information processing cannot take place - a situation which is commonly referred to as tunnel vision. The contents of the short-term memory will, then, be discarded. One way of enhancing the capacity of short-term buffer is operating a control process called chunking, in which we group individual pieces of information into larger units. Information like 867331276 is chunked into 867331 276. In reading chunking is made by reading as rapidly as possible. When information has been interpreted and makes sense, it is sent to the longterm memory, to be integrated with similar knowledge in store in the mind.

The third component of the human brain is the permanent memory. Permanent memory is also called long-term memory. Permanent memory is a place to store our knowledge of the world in mind. The knowledge of the world includes general knowledge such as the rules of grammar or of arithmetic, or memories form childhood. The memories are used to interpret new experiences, and, in turn, the new events may later be added to this storehouse of information.

The contents of permanent memory are of two kinds: semantic memory and episodic memory. Semantic memory refers to our organized knowledge of words, concepts, symbols, and objects, and information as motor skills (cycling, driving, swimming, bicycling), general knowledge (grammar, arithmetic), spatial knowledge (lay-out of rooms, offices and buildings) and social skills. Episodic memory holds information of events that are specific to a time and a place. It is the memory to keep a record of personal experiences such as what you had for breakfast this morning or where you got your first job (Carroll, 1986, pp. 44-48).

In the light of the human information processing theory, human beings solve a problem by making use of the relevant knowledge of that problem that is stored in the long term memory. In solving English grammar problems human beings use English grammar knowledge. To be specific, a tense problem is solved by knowledge of tense. A concord problem is solved by knowledge of concord. An ellipsis problem is solved by knowledge of ellipsis. A passive problem is solved by knowledge of passive voice. Hence, if a grammar test item poses two or more problems, the test item is confusing and has little merit to facilitate or aid learning. The following test item written by the language testing expert Heaton (1988, p. 29) is a grammar test item that does not facilitate learning maximally: 
I never knew where
A. had the boys gone
C. have the boys gone
B. the boys have gone
D. the boys had gone

This test item poses two problems: a problem of tense and a problem of word order. Its value to aid the learning of English grammar is low. It is desirable to split the test item into two items:

(1) I never knew where the boys ...
A. have gone.
B. had gone.
C. are going.
D. go.

(2) I never knew
A. where had the boys gone.
B. had gone where the boys.
C. the boys had gone where.
D. where the boys had gone.

But these two items must not be included in one test set as they are because item no. 2 offers a clue to solve item no. 1 .

\section{Noam Chomsky's Hypothesis - Making Theory}

According to Chomsky, human beings are born with special abstract mental mechanisms which he refers to as language acquisition device (LAD). On the basis of language input that adults speak, the language acquisition device is capable of making hypothesis about how language works, about the grammar of the language, and deriving an appropriate grammar. The language that the adults speak may be degenerate, but at the age of about six years, children arrive at an adequate grammar.

The implication of the above postulation is that correct and desirable language input will facilitate the acquisition of correct grammar. On the contrary, incorrect language input may result in imperfect grammar mastery. Referring to English grammar test items, the following teacher made test items are examples of test items that do not aid the learning of English grammar:

Sarah : "What does your uncle do?"

Tasya : "He is a
a. policemen
b. policemans
c. policeman
d. policemens 
Option b. policemans, is a non occurrent form. Option d. policemens, is also a non occurrent form. Poor students may think that these forms are correct forms in English and thus, they are misled in their study of English grammar. Instead of maintaining the above item, the following revision may be made:

Sarah : "What does your uncle do?"

Tasya : "He is a

a. policemen

b. policeman

It is not necessary to always have four options for all items as test constructors may plunge into a trap to include non-occurrent forms. The policy of having two or three options only for certain items may be taken.

The following test item has a mixed content, concord and tense:

My cousin is a salesperson. She ....
a. sell
b. are selling
c. is selling
d. sells

Option a. sell, is a problem of concord. Option b. are selling, is just the same. Option c. is selling, is tricky. The following revision is offered:

My cousin is a salesperson. She .... clothes.
a. had sold
b. will have been selling
c. will have sold
d. sells

The four options are all about tense.

\section{THE MERITS OF THE MULTIPLE CHOICE TYPE TEST ITEMS}

An English grammar subject or English structure subject teaches various kinds of English grammar rules like tenses, kinds of sentences, question forms, tag questions, elliptical sentences, concord, degrees of comparison, if - clauses, prepositions, direct - indirect speech, passive voice, perception verbs, auxiliary verbs, word order, indirect questions, adjective clauses, past participle, present participle, and subjunctive mood, to mention some. As these rules are taught, they must be tested to ensure learning. A discrete, multiple choice type of test is the only test type that 
can be devised to measure the mastery of learning of these many grammatical rules. A multiple choice type of test can be used to devise an achievement test that has a very high degree of content validity, that is, the extent to which a test measures a representative sample of the domain of task under consideration. All English teachers are supposed to know that meeting the content validity is one of the requirements for a good test.

The second merit of the multiple choice type of test is that since a multiple choice type of test may contain 200, 250, or even 300 items, every skill pertaining to a grammatical rule can be tested in three, four, five or even six items. That being the case, the degree of confidence of students' mastery of the grammatical rules is ascertained. An integrative test will not offer such an advantage.

\section{PRINCIPLES OF CONSTRUCTING MULTIPLE CHOICE TEST ITEMS}

The following are the basic guidelines for constructing multiple-choice test items:

(1) Present a single clearly formulated problem in the stem.

(2) Make certain that the intended answer is correct and clearly best.

(3) Make all alternatives grammatically consistent with the stem of the item and parallel in form.

(4) Avoid verbal clues that might enable testees to select the correct answer or to eliminate an incorrect alternative.

(5) Make certain that each item is independent of the other items in the test.

(6) Avoid tricky questions.

(7) Avoid mixed content.

(8) Avoid negative wash back through non occurrent forms.

(9) Avoid convergence and divergence cues.

(10) Put as much of the wording as possible in the stem of the item.

(11) In the assembling, items must be arranged in order of increasing difficulty.

(12) For instructional purposes, in the assembling, items of the same type should be grouped together.

It is obvious that constructing and assembling a multiple choice test set are difficult tasks to do. In addition, these activities consume much time. 
But these have to be done if the test is to be valid and contribute to students' learning process.

\section{EXAMPLES AND DISCUSSION}

The following structure test items constructed by English Department staff members have apparently not been based on the consideration to aid learning processes and need revising:

(1) The politician, smiling broadly, the stage.
a. approaching
b. approached
c. approach
d. had been approached

The stem is an active sentence and the problem that is posed is a tense problem. Option $a$. approaching, is a present participle form of a verb, not a tense form of a verb. It causes the item to have mixed contents. Option c. approach, poses a subject-verb concord problem. Option $d$. had been approached, poses a problem of passive voice. This item contains mixed contents of tense, present participle, concord and passive voice. The following is the revised version:

At 10:00 a.m. last Sunday, the politician, smiling broadly, the stage.
a. approaches
b. approached
c. is approaching
d. has approached

(2) The lawn is wet; it
a. should have
b. might
c. must
d. must have

Option b. might, is not in parallel form in the stem. Option c. must, is not in parallel form either. The suggested revision will be as follows: The lawn is wet; it last night.
a. should have rained
b. must have rained
c. has rained
d. will have rained 
(3) A shortage of workers in Thailand this year.
a. predicted
b. is being predicted
c. to predict
d. predicting

This item poses a problem of passive voice in the progressive form. Option $c$ and $d$ are not verb forms as predicators. They are undesirable. The suggested revision is:

A shortage of workers in Thailand this year.

\section{a. is predicting \\ b. is being predicted}

A passive form is contrasted with an active form to facilitate learning. It is not necessary to have four alternatives.

(4) Nurses . of patients in hospitals.
a. take care
b. takes care
c. taking care
d. took care

The word care should have been put in the stem. Option b. takes care, involves a problem of concord. Option c. taking care, is only a present participle form of verb, not a predicator form. The following is the revised version of the item:

Nurses .................. care of patients in hospitals.
a. take
b. took
c. had taken
d. will be taking

(5) We used to ................. her on our way to school.
a. meeting
b. to meet
c. meets
d. meet
e. met

Option $b, c, e$ are non occurrent forms. The problem with 'used to' is that it is followed by either a present participle form or an infinitive form without 'to'. The revised version is: 
We used to her on our way to school.
a. meeting
b. meet

(6) Marlin : "Where are you staying?”

Christ : "At Sahid Hotel."

Marlin asked Christ
a. where he stays.
b. where he was staying
c. where did he stay
d. where does he stay
e. where had he stayed

This item contains mixed contents, a problem of tense and word order. It can be split into two problems:

Marlin : "Where are you staying?"

Christ : "At Sahid Hotel.”

Marlin asked Christ where he

and:
a. stays
b. stayed
c. was staying
d. had stayed

Marlin : "Where are you staying?”

Christ " At Sahid Hotel.”

Marlin asked Christ
a. he was staying where
b. where he was staying
c. was staying where he.
d. where was he staying

(7) The woman in the kitchen is my mother.
a. to cook
b. cooked
c. cooks
d. cooking
e. is cooking

The problem posed in this item is a verb that modifies a noun. There are three kinds of verbs the modify a noun: an infinitive, a present participle and a past participle. Hence, the revised version is: 
The woman .................... in the kitchen is my mother.
a. to cook
b. cooking
c. cooked

(8) The food
a. to served
b. serving
c. to serve
d. served
e. being served

The problem posed in this item is the same as that in no. (7). In addition, to served is a non occurrent form. The revised item is:

The food yesterday was sour.
a. serving
b. served

Alternative 'to serve' is not included because the sentence. The food to serve yesterday was sour is a correct sentence, with a meaning that the food was not yet served.

(9) She ............... the letter when Anton entered the room.
a. was typing
b. to type
c. typing
d. typed
e. types

This item has mixed contents: finite predicates: was typing, typed, and types, and non-finite verb forms: to type and typing. The suggested revision is:

She the letter when Anton entered the room.
a. was typing
b. is typing
c. typed
d. has typed

(10)If he had prepared his lesson, he his examination.
a. passed
b. would have passed
c. would be passed
d. would pass
e. had passed 
Option c. would be passed, is a passive predicate. It is suggested that the options related to the verb forms of if-clauses. Here is the suggested revision:

If he had prepared his lesson, he ...................... his examination.
a. passes
b. will pass
c. would pass
d. would have passed

(11)“Bambang looks very happy today.”

"Don't you know he to General Manager?”
a. has promoted
b. to be promoted
c. being promoted
d. has to promote
e. has been promoted

Option b. to be promoted, and c. being promoted, are not finite verbs as predicates. This item is solved by the knowledge of either active verbs or passive verbs. So, the revision is:

"Bambang look very happy today."

"Don't you know he to General Manager?”

a. has promoted

b. has been promoted

(12) "Several hotels in this region are closing down." "That's because tourism itself since last year.”
a. is declining
b. had declining
c. declined
d. was declining
e. has been declining

Option b. had declining, is a non occurrent form and has to be omitted. The following is the revision:

"Several hotels in this region are closing down."

"That's because tourism itself since last year." 
(13) "Why are you going to the doctor?”

a. is declining

b. declined

c. was declining

d. has been declining

"I'm going to have my eyes ....
a. to examine
b. examining
c. examination
d. examined

Option c. examination, is a noun. It is not in parallel form with the other options. This item must be revised to result in:

"Why are you going to the doctor?"

"I'm going to have my eyes
a. to examine
b. examining
c. examined

(13) “When will you return?”

"I'll be back ....
a. in a couple week
b. in a few day
c. as soon possible
d. the day after tomorrow

Options $a, b$, and $c$ are non occurrent forms. It is suggested that these options be omitted. The problem posed in this item is too easy to test and need not be tested.

(14) "Who bridge the best of all?"

"It's hard to say."
a. plays
b. can plays
c. play
d. does play

Option b. can plays, is a non occurrent form. Alternative c. play, poses a problem of concord. This item may be revised to produce:

"Who ... bridge the best of all?” "It's hard to say."
a. plays
b. does play 
(15) “Why is Janet so spoiled?” "She is accustomed to .... . whatever she wants.”
a. have
b. had
c. she has
d. having

Alternative $c$. she has, is not in parallel form with the other options. The problem in this item is that 'is accustomed to' is followed by either an infinitive form, a present participle form, or a past participle form. The following is the revision:

"Why is Janet so spoiled?"

"She is accustomed to whatever she wants.”
a. have
b. having
c. had

(16) “Johnny is supposed to visit me this afternoon.” "If he tell him I said 'hello'."
a. coming
b. came
c. comes
d. will come

Alternative $a$. coming, is not a finite form of the predicate and may strengthen the wrong learning of 'If he coming' which is numerous. This item may be revised to produce:

"Johnny is supposed to visit me this afternoon." "If he ... , tell him I said 'hello'.”
a. had come
b. came
c. comes
d. will come

\section{CONCLUSION}

Multiple choice tests must be used in achievement testing because this test type guarantees the fulfillment of the requirement of content validity of achievement tests. In constructing multiple choice test items, alternatives must, as far as possible, center around the relevant knowledge in the long term memory since, according to the theory of human information 
processing, learners make use of the relevant knowledge in the long term memory to solve a particular test item. In so doing, the selection of the correct alternative will soon strengthen correct learning and the elimination of incorrect alternatives will immediately disconfirm incorrect learning. In addition, according to Chomsky's hypothesis - making theory, learners process language data by making hypothesis about the grammar of the language. Faulty language data through the use of non occurrent forms in multiple choice test items will certainly not facilitate learning processes. Instead, they will confuse and mislead learning processes. Non occurrent forms in multiple choice items must be totally avoided.

\section{REFERENCES}

Brown, J. D. (1996). Testing in language programs. New Jersey: Prentice Hall.

Carroll, D. W. (1986). Psychology of language. Belmont: Wadsworth.

Doughty, C., \& Williams, J. (2004). Focus on form in classroom second language acquisition. Cambridge: Cambridge University Press.

Gleason, J. B., \& Ratner, N. B. (1998). Psycholinguistics (2 ${ }^{\text {nd }}$ ed.). Fort Worth: Harcourt Brace College Publishers.

Gronlund, N. E. (1977). Constructing achievement tests ( $2^{\text {nd }}$ ed.). Englewood Cliffs: Prentice-Hall.

Heaton, J. B. (1988). Writing English language tests. London: Longman Group.

Hinkel. E. (2006). Current perspectives on teaching the four skills. TESOL Quarterly, 40(1), 109-131.

Adisutrisno, D. W. (1984). The 1982-1983 English entrance test of the English department, Teacher Training College, Widya Mandala Catholic University, Surabaya, Indonesia: An analysis of its validity. Unpublished M.A. Thesis, Widya Mandala Catholic University, Surabaya, Indonesia. 